Article

\title{
Solvent-Free Lipase-Catalyzed Synthesis of Technical-Grade Sugar Esters and Evaluation of Their Physicochemical and Bioactive Properties
}

\author{
Ran Ye ${ }^{1}$, Douglas G. Hayes ${ }^{1, *}$, Rachel Burton ${ }^{2}$, Anjun Liu ${ }^{3}$, Federico M. Harte ${ }^{4}$ and \\ Yuemeng Wang ${ }^{3}$ \\ 1 Department of Biosystems Engineering and Soil Science, University of Tennessee, \\ Knoxville, TN 37996-4531, USA; acmilanyr@yahoo.com \\ 2 MARC-IV Consulting Inc., 101 East Main Street, Kearney, MO 64060, USA; rburton@marciv.com \\ 3 Key Laboratory of Food Nutrition and Safety, Ministry of Education, College of Food Engineering \\ and Biotechnology, Tianjin University of Science and Technology, Tianjin 300457, China; \\ laj@tust.edu.cn (A.L.); wangyuemeng1990@163.com (Y.W.) \\ 4 Department of Food Science, Pennsylvania State University, University Park, PA 16802, USA; \\ fmh14@psu.edu \\ * Correspondence: dhayesl@utk.edu; Tel.: +1-865-974-7991
}

Academic Editors: David D. Boehr and Keith Hohn

Received: 24 March 2016; Accepted: 17 May 2016; Published: 30 May 2016

\begin{abstract}
Technical-grade oleic acid esters of sucrose and fructose were prepared using solvent-free biocatalysis at $65{ }^{\circ} \mathrm{C}$, without any downstream purification applied, and their physicochemical and bioactivity-related properties were evaluated and compared to a commercially available sucrose laurate emulsifier. To increase the conversion of sucrose and fructose oleate, prepared previously using solvent-free lipase-catalyzed esterification catalyzed by Rhizomucor miehei lipase ( $81 \%$ and $83 \%$ ester, respectively), the enzymatic reaction conditions was continued using $\mathrm{CaSO}_{4}$ to control the reactor's air headspace and a lipase (from Candida antarctica $B$ ) with a hydrophobic immobilization matrix to provide an ultralow water activity, and high-pressure homogenation, to form metastable suspensions of 2.0-3.3 micron sized saccharide particles in liquid-phase reaction media. These measures led to increased ester content of $89 \%$ and $96 \%$ for reactions involving sucrose and fructose, respectively. The monoester content among the esters decreased from $90 \%$ to $<70 \%$ due to differences in regioselectivity between the lipases. The resultant technical-grade sucrose and fructose lowered the surface tension to $<30 \mathrm{mN} / \mathrm{m}$, and possessed excellent emulsification capability and stability over $36 \mathrm{~h}$ using hexadecane and dodecane as oils, comparable to that of sucrose laurate and Tween ${ }^{\circledR}$ 80). The technical-grade sugar esters, particularly fructose oleate, more effectively inhibited gram-positive foodborne pathogens (Lactobacillus plantarum, Pediococcus pentosaceus and Bacillus subtilis). Furthermore, all three sugar esters displayed antitumor activity, particularly the two sucrose esters. This study demonstrates the importance of controlling the biocatalysts' water activity to achieve high conversion, the impact of a lipase's regioselectivity in dictating product distribution, and the use of solvent-free biocatalysis to important biobased surfactants useful in foods, cosmetics, personal care products, and medicine.
\end{abstract}

Keywords: antimicrobial activity; antitumor activity; emulsification; high-pressure homogenation; lipase; sugar-fatty acid esters; surfactants

\section{Introduction}

Saccharide-fatty acid esters are biodegradable, biocompatible and environmentally-friendly biobased surfactants and emulsifiers [1-3]. Saccharide esters enriched in monoester have been widely 
used as emulsifiers in the food, cosmetic and pharmaceutical industries, and as agents for drug delivery $[4,5]$. In addition, they possess antimicrobial, antitumor, and anti-human immunodeficiency virus (HIV) activity [6,7]. Moreover, they have been employed to form drug-delivery systems [4,5]. The conventional method for their chemical synthesis involves extreme reaction conditions; for instance, high temperature, the use of solvents such as dimethylformamide and dimethylsulfoxide, and alkali or acid catalysts [8]. In contrast, biocatalytic synthesis is operated under mild reaction conditions, thereby reducing the formation of undesirable byproducts and lowering energy consumption during processing [9-11]. However, the poor miscibility of hydrophobic acyl donors and hydrophilic acceptors leads to a slow reaction rate. Different means have been developed to enhance miscibility of acyl donors and acceptors for lipase catalyzed reactions, including, polar organic solvents such as tert-butanol [12], ionic liquids [13], and ultrasound irradiation [14]. However, these methods suffer from some deficiencies, for instance, the usage of expensive equipment and solvents, downstream separation challenges and costs, environmental issues, and safety concerns.

In our laboratory, we developed a sustainable approach to produce saccharide-fatty acid esters in solvent-free media, by forming metastable suspensions of 10-100 $\mu \mathrm{m}$-sized saccharide particles at $1-2 \mathrm{wt} \%$. The production of sugar esters further improves the maximum concentration and stability of the suspended saccharide particles [15-19]. We utilized the solvent-free suspension-based medium in a closed-loop bioreactor system operated under continuous recirculation at $53^{\circ} \mathrm{C}$ to prepare sugar esters on a 30 gram scale. The system contained a peristaltic pump, a packed-bed bioreactor (PBBR) filled with immobilized Rhizomucor miehei lipase (RML), and a reservoir open to the atmosphere, which allowed for free evaporation of the co-product water during the first stage of the reaction. During the time course of reaction, additional acyl acceptor was added periodically by temporarily removing the solvent-free media from the bioreactor system, and adding saccharide particles under stirring. When reaching approximately $60 \mathrm{wt} \%$ ester, a stronger water removal method was introduced to increase the yield, e.g., the combination of $\mathrm{N}_{2}$ bubbling and vacuum pressure or molecular sieves, which decreased the water concentration in the liquid phase from $\sim 0.8 \mathrm{wt} \%$ to $\sim 0.4 \mathrm{wt} \%$. This approach generated a yield 69 92 wt \% esters within $132 \mathrm{~h}$. Recently, the combination of high-speed homogenization and high-intensity ultrasound was utilized to reduce the particle size of sucrose crystals five-fold, enhancing the rate and extent of reaction [20].

The Food and Agriculture Organization (FAO) of the European Union specifies that sucrose esters contain no solvents, and fatty acid and sucrose at amounts $<3 \mathrm{wt} \%$ and $<5 \mathrm{wt} \%$, respectively [21]. Therefore, in order to meet the FAO requirements without the need for downstream purification, the yield for the authors' solvent-free enzymatic approach needs to be increased. Therefore, the first objective of this work is to increase the conversion of lipase-catalyzed synthesis of fructose and sucrose oleate (i.e., to meet the FOA requirements) by introducing three new approaches during the latter stage of reaction (i.e., upon achieving $\sim 80 \%-85 \%$ conversion using the approach described above). First, high-pressure homogenation (HPH) will be employed to provide $\mu \mathrm{m}$ sized suspensions of saccharide particles. Second, $\mathrm{CaSO}_{4}$ will be used to further reduce the water activity of the bioreactor through its control of the water activity for the reactor's air headspace. Third, immobilized Candida antarctica lipase B (CALB) will be employed rather than RML because the former possesses a lower water content due to its more hydrophobic immobilization matrix, polyacrylate [22]. The lower water content of the enzyme's microenvironment is anticipated to increase the equilibrium conversion. The second objective is to test the hypothesis that the sugar esters produced from the approach described above will perform well as an emulsifier and as antimicrobial and antitumor agents without the need of further purification.

\section{Results and Discussion}

\subsection{Lipase-Catalyzed Synthesis of Technical-Grade Sucrose and Fructose Oleate}

In order to improve the final yield of sugar fatty ester and the rate during the latter stage of the reaction, three strategies were implemented: the replacement of RML with CALB, use of $\mathrm{CaSO}_{4}$ 
to lower the water activity of the bioreactor's air headspace, and HPH to reduce the particle size of suspended saccharide, hence increasing the concentration of saccharide in the reaction medium. $\mathrm{HPH}$ reduced the particle sizes of saccharide crystals in the solvent-free suspension media from $91.5 \pm 2.8 \mu \mathrm{m}$ to $2.1 \pm 0.6 \mu \mathrm{m}$ for fructose oleate and $98.7 \pm 2.1 \mu \mathrm{m}$ to $3.3 \pm 0.8 \mu \mathrm{m}$ for sucrose oleate (data not shown), a 6-7-fold reduction in particle size than that produced by high-speed homogenation plus ultrasound [20]. Figure 1 depicts the time course of sucrose and fructose-oleic acid esterification after implementation of the three strategies. The conversion of fructose and sucrose oleate increased from approximately $83 \%$ to $96 \%$ and from $80 \%$ to $89 \%$, respectively, in a four-day period. The productivity for ester production for the reactions depicted in Figure 1A-D were $0.035 \mathrm{mmol} \cdot \mathrm{h}^{-1} \cdot \mathrm{g}_{\text {lipase }}{ }^{-1}$ and $0.025 \mathrm{mmol} \cdot \mathrm{h}^{-1} \cdot \mathrm{g}_{\text {lipase }}{ }^{-1}$ for fructose and sucrose oleate, respectively. The former productivity is one order of magnitude higher than that obtained during the final stage of reaction ( $~ 82 \%$ to $\sim 88 \%$ ester) in our previous publications, $0.0014-0.0017 \mathrm{mmol} \cdot \mathrm{h}^{-1}$. glipase $^{-1}[15,16]$, and comparable to the productivity of lipase-catalyzed synthesis of sucrose palmitate in the presence of a 2-methyl-2-butanol/dimethylsulfoxide mixture [23]. The presence of $\mathrm{CaSO}_{4}$ reduced the water concentration from $0.49 \%$ to $0.09 \%$ for fructose oleate and from $0.51 \%$ to $0.12 \%$ for sucrose oleate (Figure 1B). In our previous studies, when reaching $~ 60 \%$ conversion, molecular sieves were introduced to the esterification reaction to decrease the water concentration from $\sim 0.92 \%$ to $\sim 0.41 \%$ [16]. Although a large amount of molecular sieves further decreased the water concentration to approximately $0.10 \mathrm{wt} \%$ in the cited study, a concern with this approach is that debris, which commonly forms from shear-induced abrasion of the molecular sieves is likely to adsorb onto the immobilized lipase, thereby reducing the biocatalytic activity [16]. The saccharide concentration in the liquid phase of the reaction medium decreased during the time course of reaction due to its consumption by the reaction; however, saccharide was not completely consumed (Figure 1C). It appears that the ultra-low water concentration did not negatively affect CALB activity, in agreement with the results in literature [20,24]. As shown in Figure 1D, the proportion of monoester decreased during the time course of both reactions, from $90 \%$ to $60 \%-70 \%$. The decrease is attributable to differences in the inherent regioselectivity between CALB and RML $[25,26]$, the latter used to prepare the initial reaction medium. An additional factor is the lower water concentration for CALB due to its more hydrophobic immobilization matrix, which results in the more hydrophobic microenvironment for the enzyme, thereby enhancing the transformation of monoester into diester [20,27]. Upon completion of the biochemical reactions, the only purification enacted was the removal of CALB by sedimentation.

\subsection{Composition and Surface Activity}

Compositional profiles and surface activity-related properties for technical-grade fructose and sucrose oleate, prepared as described above, and for two commercially available surfactants, sucrose laurate and Tween ${ }^{\circledR} 80$, serving as positive and negative controls, respectively, are given in Table 1. Sucrose laurate was highly pure, containing only $0.1 \%$ free fatty acid and no detectable saccharide; in contrast, fructose and sucrose oleate contained $3.4 \%$ and $10.0 \%$ free fatty acid, respectively, and $0.5 \%-1.0 \%$ saccharide. Sucrose laurate was more highly enriched in monoesters, $86 \%$ among the esters, compared to $65 \%-69 \%$ for the technical-grade enzymatic products, therefore yielding a slightly lower hydrophilic-lipophilic balance (HLB) value for sucrose oleate (10.1) compared to sucrose laurate (11.2). The HLB of fructose oleate is only 7.2, due to the presence of only one saccharide unit per molecule. Plot of surfactant concentration, $C$ (log scale), vs. surface tension, $\gamma$, for the three sugar esters resembled plots frequently encountered for surfactants: a linear decrease of $\gamma$ vs. $\log C$ at low $C$, and a constant, minimal $\gamma$ at high $C$ (Figure 2). Parameters derived from the Figure 2 plots-the critical micellar concentration $(\mathrm{CMC}), \gamma($ at $C=\mathrm{CMC})$, the surface excess $(\Gamma)$, and the surface area per surfactant $\left(A_{\mathrm{s}}\right)$ are given in Table 1 [28-30]. The surface tension for sucrose laurate achieved by us $19.7 \mathrm{mN} / \mathrm{m}$, is lower than values reported for the same ester in the literature, 35-40 mN/m [31-33]; also, the CMC reported in Table $1(0.63 \mathrm{~g} / \mathrm{L})$ is higher than reported values, $0.1-0.2 \mathrm{~g} / \mathrm{L}[24,31,33]$, with the lower temperature used in our studies $\left(22^{\circ} \mathrm{C}\right)$ compared to those used in the cited reports $\left(25-37^{\circ} \mathrm{C}\right)$ being at least partially attributable to the latter difference [34]. Compared to sucrose laurate, technical-grade 
sucrose oleate yielded a slightly higher $\gamma(29.6 \mathrm{mN} / \mathrm{m})$ and a higher CMC, the latter trend reflecting the lower purity and polarity for sucrose oleate [31,34]. For fructose oleate, its $\gamma$ value $(27.9 \mathrm{mN} / \mathrm{m})$ is comparable to those reported in the literature for fructose caprate, laurate and myristate [30,32]. In summary, the technical-grade sugar esters prepared using solvent-free enzymology are effective surfactants, able to lower the surface tension to a similar extent as commercially available and more highly purified sugar esters.
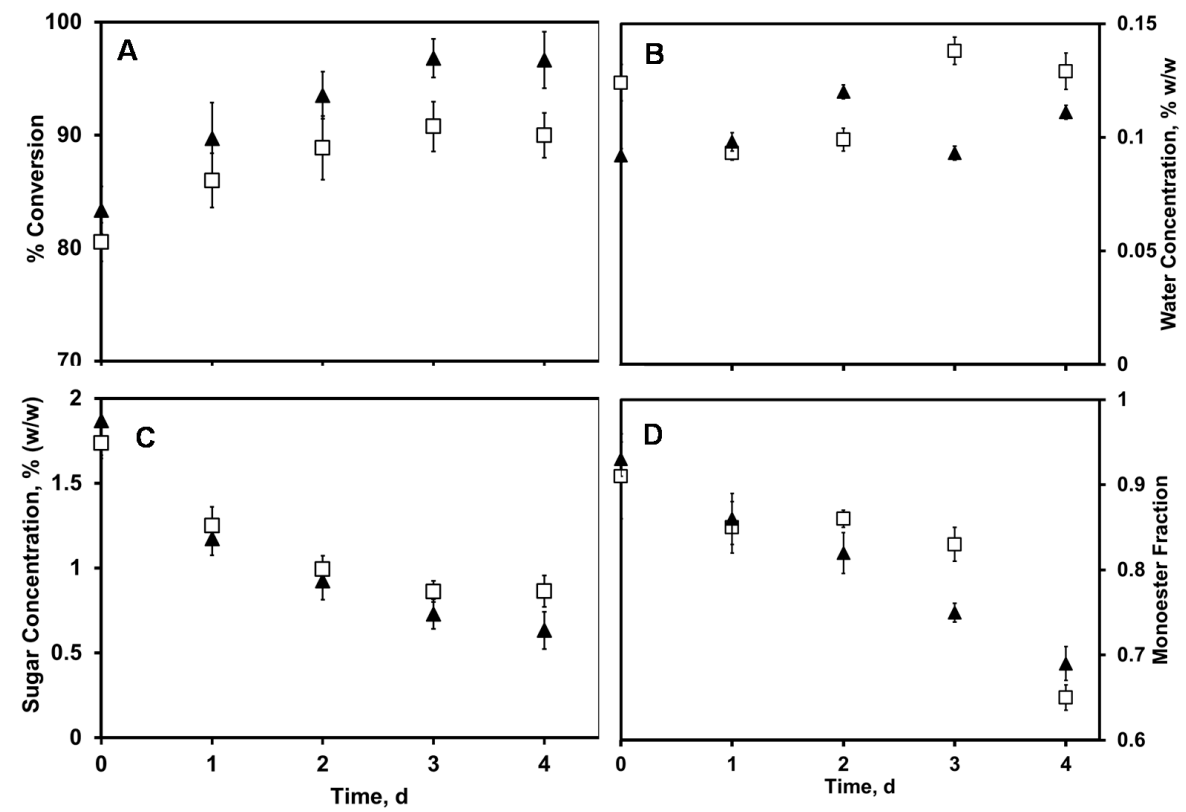

Figure 1. Time courses of the lipase-catalyzed synthesis of fructose oleate (triangle) and sucrose oleate (square): (A) conversion of oleic acid; (B) water concentration; (C) saccharide concentration; and (D) fraction of monoester among all esters. Reaction conditions: $20 \mathrm{~g}$ of a solvent-free suspension of saccharide particles in solvent-free reaction media (prepared via Rhizomucor miehei lipase (RML)-catalyzed esterification), prepared via high-pressure homogenation (HPH), was mixed with $2 \mathrm{~g}$ of Candida antarctica lipase B (CALB). The reaction was conducted in a closed stirred system using $\mathrm{CaSO}_{4}$ to lower the water activity of the bioreactor head space at $65^{\circ} \mathrm{C}$ and a stir rate of $350 \mathrm{rpm}$.

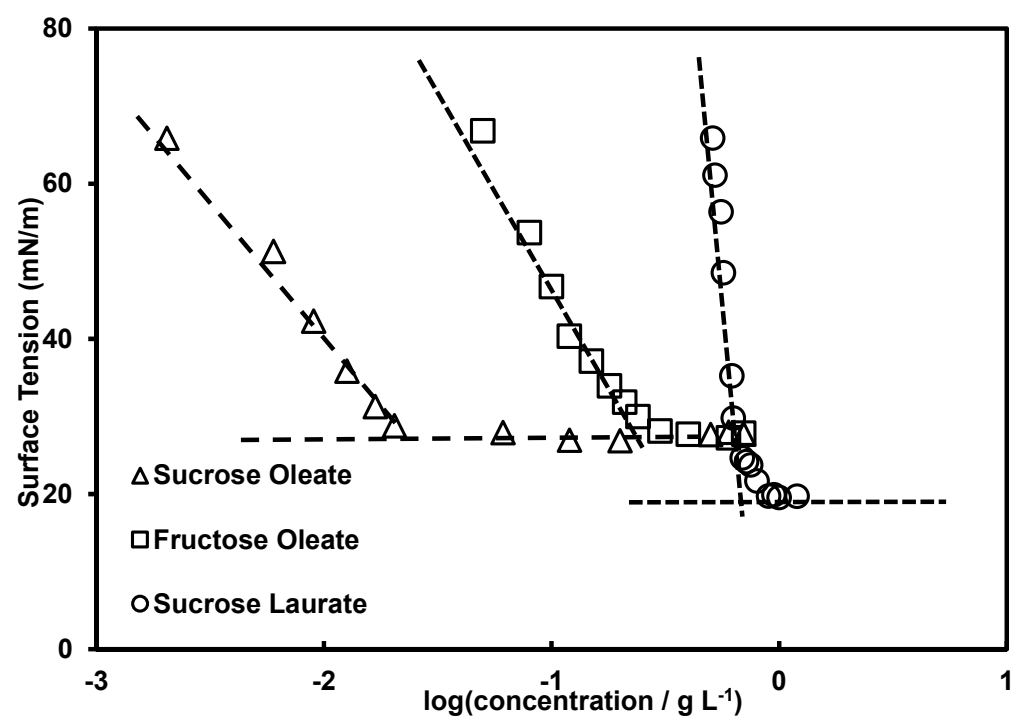

Figure 2. Surface tension $(\gamma)$ at $22{ }^{\circ} \mathrm{C}$ vs. concentration $(C)$ for sugar esters: sucrose oleate $(\Delta)$, fructose oleate $(\square)$, and sucrose laurate $(\bigcirc)$.Intersection of the dashed lines represent determination of the critical micellar concentration (CMC). 
Table 1. Comparison of chemical and surfactant-related properties of sucrose oleate and fructose oleate, prepared from the enzymatic reaction, versus sucrose laurate and Tween ${ }^{\circledR} 80^{1}$, commercial emulsifiers, at $22{ }^{\circ} \mathrm{C}$.

\begin{tabular}{ccccc}
\hline Property & Fructose Oleate & Sucrose Oleate & Sucrose Laurate & Tween $^{\circledR} \mathbf{8 0}^{\mathbf{1 - 3}}$ \\
\hline Free fatty acid, $\mathrm{wt} \%$ & 3.4 & 10.0 & 0.1 & ND \\
Saccharide, $\mathrm{wt} \%$ & 0.63 & 0.86 & $<0.10$ & ND \\
Moisture, $\mathrm{wt} \%$ & 0.11 & 0.13 & 0.05 & ND \\
Monoester among the esters, $\mathrm{wt} \%$ & 69 & 65 & 86 & $\mathrm{ND}$ \\
Density, g/mL & 7.2 & 10.1 & 11.2 & 15.0 \\
Hydrophilic-Lipophilic Balance $\mathrm{Griffin} \mathrm{HLB})$ & 934 & 952 & 689 & 1070 \\
Critical Micellar Concentration $(\mathrm{CMC}), \mathrm{g} / \mathrm{L}$ & 0.18 & 0.021 & 0.63 & 0.014 \\
Surface tension $(\gamma)$ at $\mathrm{C}=\mathrm{CMC}, \mathrm{mN} / \mathrm{m})$ & 27.9 & 29.6 & 19.7 & 38.0 \\
Surface excess $(\Gamma), \mathrm{mol} \cdot \mathrm{m}^{-2} \times 10^{6}$ & 1.91 & 0.849 & 8.19 & 0.74 \\
Specific surface area $\left(A_{\mathrm{s}}\right), \mathrm{nm}^{2}$ & 0.87 & 1.96 & 0.20 & 2.24 \\
\hline
\end{tabular}

${ }^{1}$ Polyoxyethylene (20) sorbitan monooleate; ${ }^{2}$ properties Taken from references [28,29]; ${ }^{3}$ ND refers to "not determined"; 4 Hydrophilic-lipophilic balance; calculated by the following formula [30]: HLB $=20 \times$ Hydrophilic group molecular weight/Total surfactant molecular weight.

\subsection{Composition and Surface Activity}

The literature demonstrates that sugar esters are useful emulsifiers of oil in water [30,35]. Figure 3 compares the ability of the technical-grade sugar esters and controls to emulsify hexadecane and dodecane in water, and the stability of the emulsions. The figure shows that all of the sugar esters exhibited excellent emulsification ability and stability over $36 \mathrm{~h}$ for both oils, indicating that the enzymatic preparation produced an effective foam-stabilizer and emulsifier agent. The absorbance values for emulsified hexadecane were slightly greater than those for dodecane, indicating the degree of emulsification was higher for the former oil, due to its higher lipophilicity. Sucrose laurate generated the highest degree of emulsification for both oils, probably reflecting its higher monoester content among the sugar esters. In contrast, Tween ${ }^{\circledR} 80$, a common nonionic surfactant widely used in foods, cosmetics and pharmaceutics, serving as a negative control, produced the lowest absorbance values, due to its higher polarity (higher HLB, Table 1). Emulsification was slightly higher for fructose oleate than for sucrose oleate, perhaps reflecting the former's higher purity. Except for the emulsification of dodecane by sucrose oleate, which underwent a $26.9 \%$ decrease of absorbance in $36 \mathrm{~h}$ (perhaps due to its lower purity), the percent decrease for all other surfactant/oil combinations was only $10.9 \%-18.1 \%$. Our results contrast the report in the literature that an increase of diester fraction lowers the emulsion stability [30]. In summary, the technical-grade sugar esters prepared from solvent-free biocatalysis in the absence of purification performed well as emulsifiers.

\subsection{Antimicrobial Activity}

In the literature, the antimicrobial activity of sugar fatty acid esters have been evaluated, including sucrose monolaurate [36-38], lactose monolaurate [37,38], fructose dilaurate [36], and $6^{\prime}$-O-lauroylmaltose [39]. However, the antimicrobial properties of fructose and sucrose oleate have not been reported. As displayed in Figure 4, all three sugar esters inhibited the growth of gram-positive food-borne pathogens. Fructose oleate displayed higher antimicrobial activity against Lactobacillus plantarum, Pediococcus pentosaceus, and Bacillus subtilis than that of the two sucrose esters. However, the sucrose esters more strongly inhibited the growth of Staphylococcus aureus than fructose oleate. In addition, the sugar esters prevented growth of Pediococcus pentosaceus and Bacillus subtilis to an increasing extent as the concentration of sugar esters was increased; however, when the concentration exceeded $0.5 \mathrm{mg} / \mathrm{mL}$, no significant improvement of microbial inhibition by Lactobacillus platarum was observed. In summary, sugar esters prepared via solvent-free biocatalysis had equal or superior antimicrobial activity compared to commercially available sucrose laurate. 

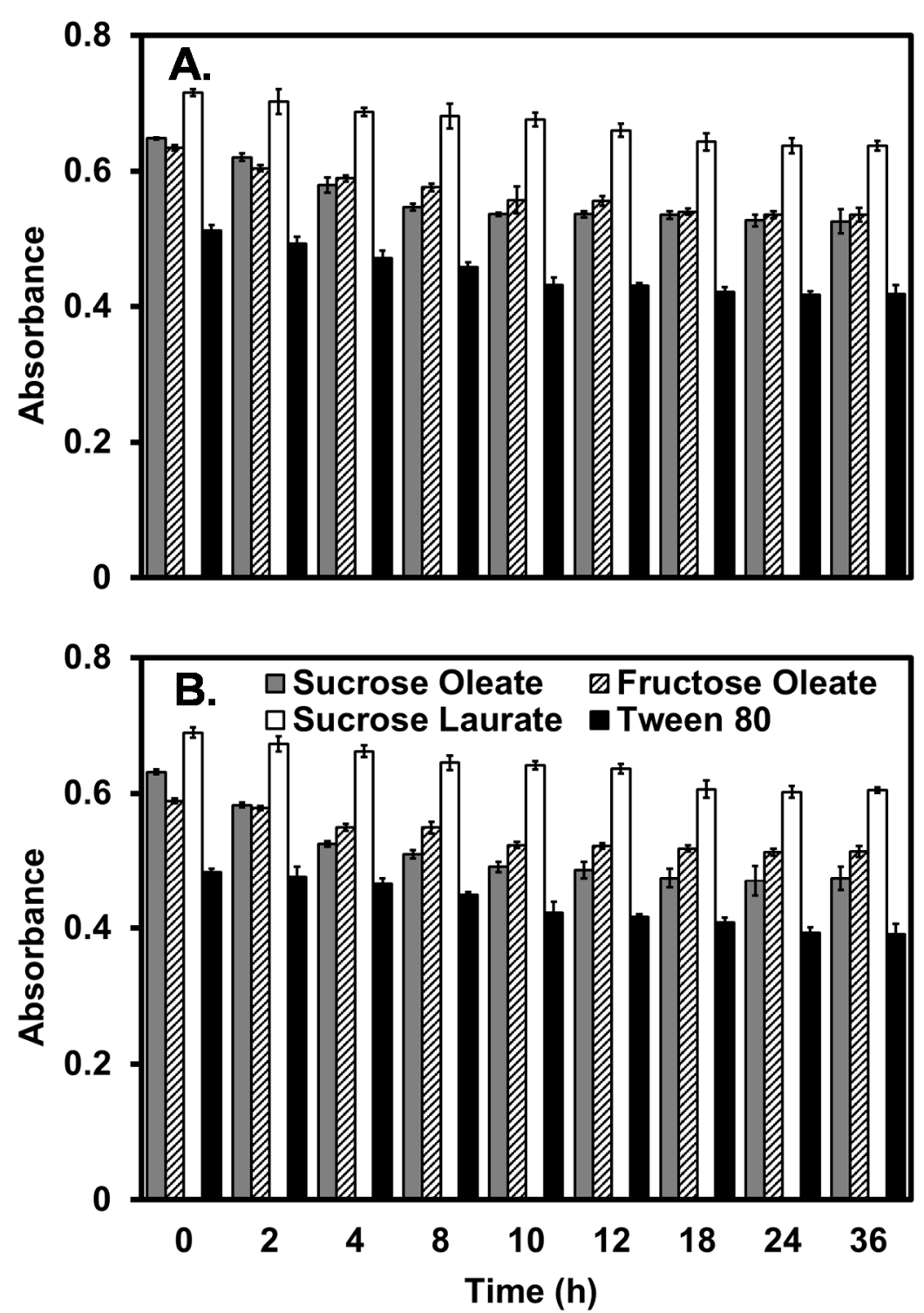

Figure 3. Emulsification of (A) hexadecane and (B) dodecane by sugar esters: sucrose oleate (gray); fructose oleate (slash); sucrose laurate (white); and Tween ${ }^{\circledR} 80$ (black; a control) at $22{ }^{\circ} \mathrm{C}$, evaluated over a $36 \mathrm{~h}$ period. Aqueous solutions of $2 \mathrm{~g} / \mathrm{L}$ sugar ester were vigorously mixed with oil, then allowed to settle in the absence of stirring for $20 \mathrm{~min}$. The turbidity of the sample was measured via absorbance at $600 \mathrm{~nm}$.

The antimicrobial mechanism of sugar esters still remains unknown. One hypothesis is that sugar esters disrupt of the cell membrane [40]. The change of cellular morphology would alter the membranes' permeability, thereby yielding a selective loss of glycolytic intermediates and inducing autolytic processes, which would result in cell death [39,41]. The inhibitory activity of sugar esters is highly associated with the acyl acceptor, the chain length and double bonds of acyl donor (fatty acids), and the degree of esterification [37]. 


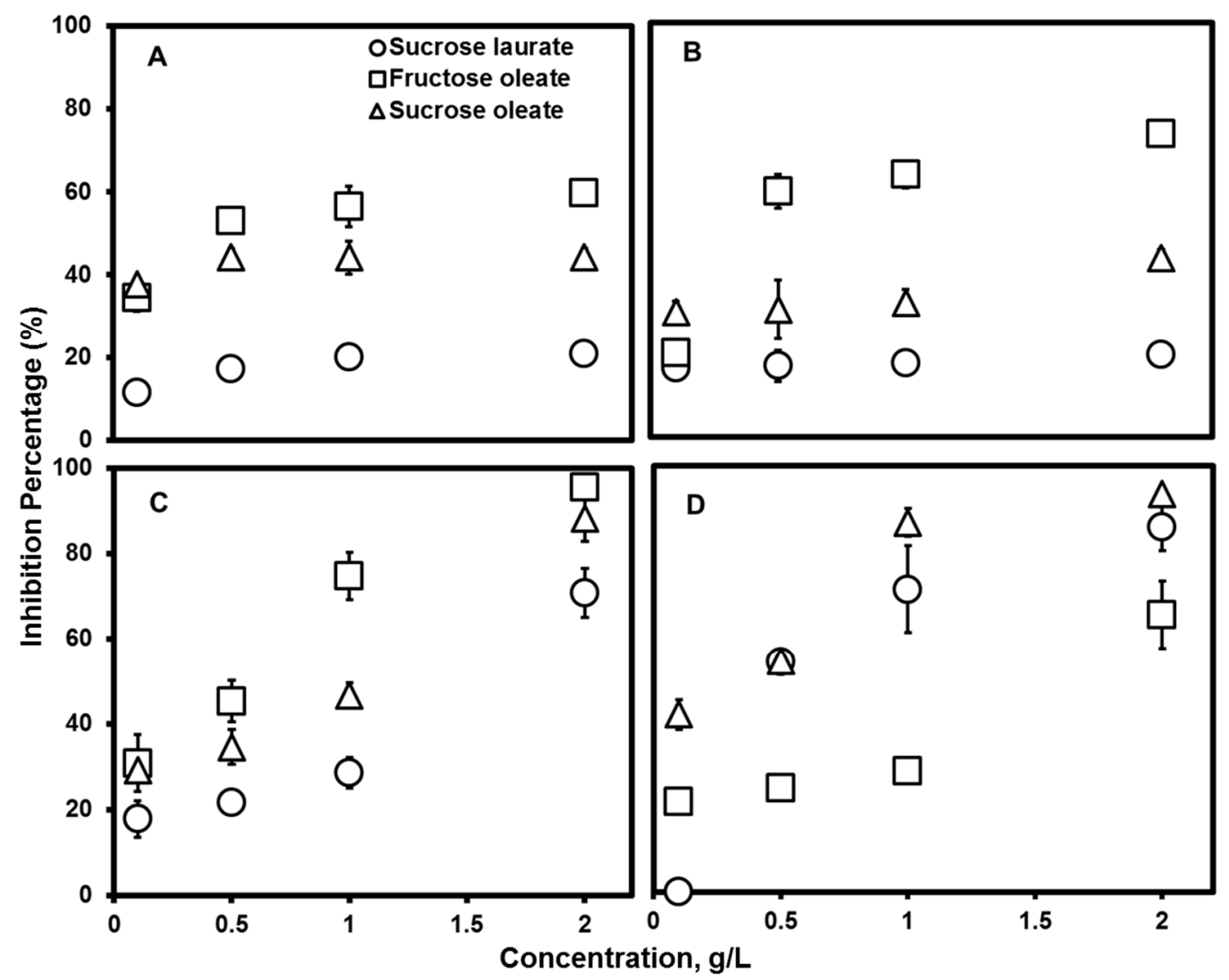

Figure 4. Antimicrobial activities of sugar fatty acid esters: sucrose oleate $(\bigcirc)$, fructose oleate ( $\square$ ), and sucrose laurate $(\Delta)$ against: (A) Lactobacillus plantarum; (B) Pediococcus pentosaceus; (C) Bacillus subtilis; and (D) Staphylococcus aureus.

\subsection{Antitumor Activity}

As plotted in Figure 5, the antitumor activity of sugar esters increased with the increase of the concentration, with the viability decreased to $<50 \%$ with the addition of either of the two sucrose esters at $1.2 \mathrm{~g} / \mathrm{L}$. No significant difference between sucrose oleate and sucrose laurate on the inhibition of tumor cell growth and proliferation were detected in this study. Kato et al. revealed that the presence of sucrose oleate and sucrose laurate allowed for the inhibition of the tumor cells [42]. It was proposed that the lipid chain of sugar fatty acid esters could attack the cell, giving rise to the esters' antitumor activity [42]. Ferrer et al. stated that the enzymatically-synthesized 6"-O-palmitoylmaltotriose could suppress two human hepatocarcinoma cancer cell lines, Hep- $\mathrm{G}_{2}$ and HeLa, derived from a human hepatoma [43]. Of interest, at the same concentration, the antitumor activities of fructose oleate are inferior to those of the sucrose esters. The difference may be attributable to the esters' degree of glycosylation, since disaccharides are often more effective inhibitors of tumor hepatocytes cells than monosaccharides [43]. In addition, another study showed that the antitumor activity of sugar esters formed from long-chain fatty acids (e.g., stearic, palmitic and myristic acid) were superior to those formed from medium-chain fatty acids (e.g., laurate and caprylate acid) [44]. 


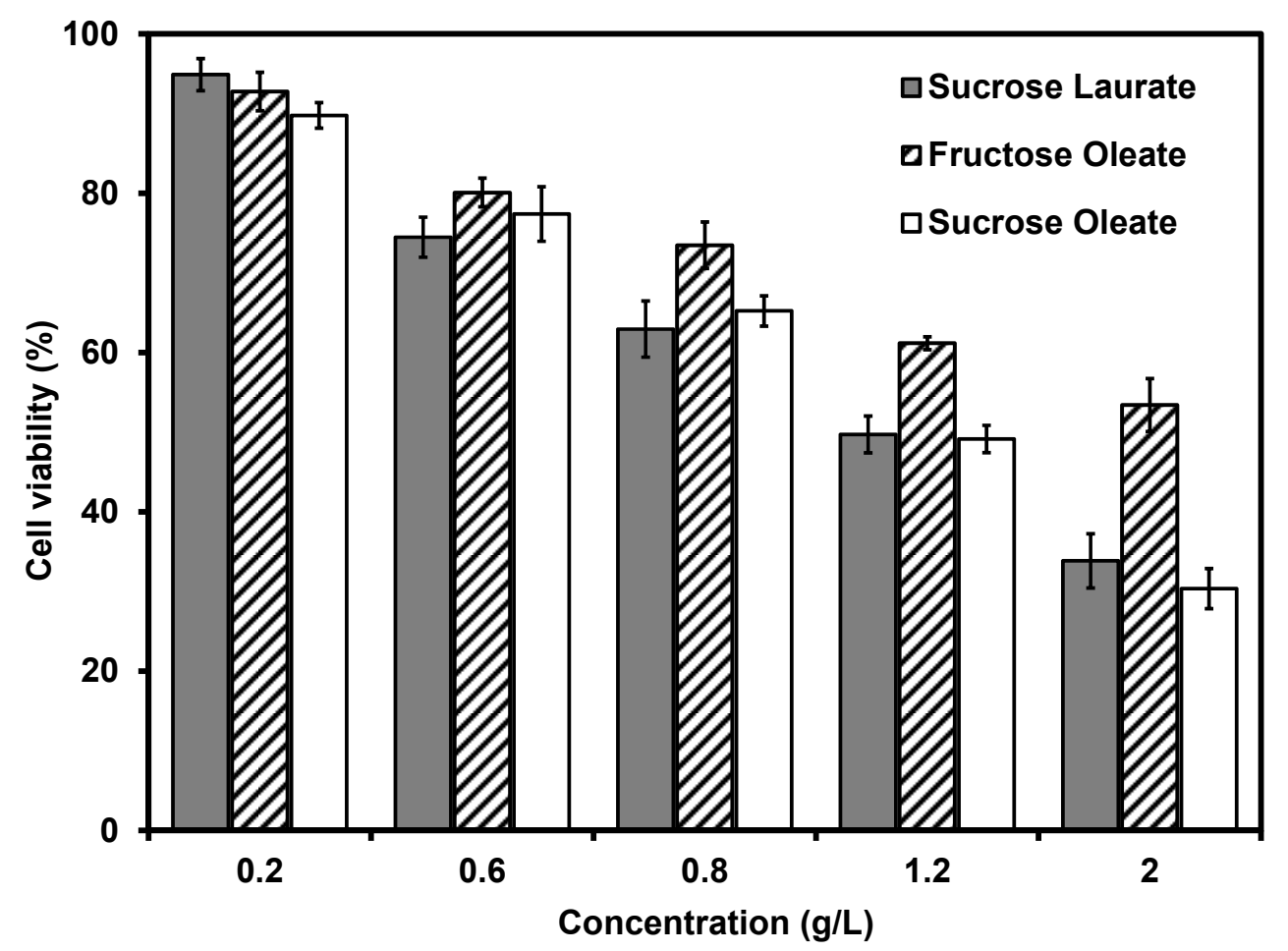

Figure 5. Antitumor activities of sugar fatty acid esters on ascitic tumor cells of Ehrlich carcinoma: sucrose laurate (black); fructose oleate (slash); and sucrose oleate (white).

\section{Experimental Section}

\subsection{Materials and Methods}

Novozym ${ }^{\circledR} 435$, Lipase B from Candida antarctica (CALB) immobilized onto macroporous acrylic resin beads 10,000 propyl laurate unit (PLU)/g, where 1 PLU refers to the amount of enzyme which forms $1 \mu \mathrm{mol} / \mathrm{min}$ of propyl laurate during esterification at $60{ }^{\circ} \mathrm{C}$, was kindly donated by Novozymes (Franklinton, NC, USA). Sucrose and fructose ( $>98 \%$ purity), acetone (high-performance liquid chromatography (HPLC)-grade), acetonitrile (HPLC-grade), methanol (HPLC grade, $0.04 w / w$ water content) and molecular sieves (Type 3A, 4-8 mesh, Grade 562) were obtained from Fisher Scientific (Pittsburgh, PA, USA). Sucrose laurate was purchased from Modernist Pantry (purity $>99 \%$, Portsmouth, NH, USA). Tween ${ }^{\circledR} 80$, polyoxyethylene (20) sorbitan monooleate, was obtained from Sigma-Aldrich (St. Louis, MO, USA). Deionized water was used throughout and all materials were used without further purification. Crude grades of sugar esters-sucrose oleate, consisting of $80.5 \mathrm{wt} \%$ ester (of which $92.5 \%$ is monoester and $7.5 \%$ diester), and $19.5 \mathrm{wt} \%$ oleic acid, and sucrose oleate, containing $83.4 \mathrm{wt} \%$ ester (91.2\% monoester, $8.8 \%$ diester) and $16.6 \mathrm{wt} \%$ oleic acid-were synthesized under solvent-free conditions, using a bioreactor system, operated under continuous recirculation, with a PBBR containing RML [15]. Microorganisms and the Ehrlich ascites tumor cell line were purchased from American Type Culture Collection (Manassas, VA, USA).

\subsection{Formation of Supersaturated Solutions of Size-Reduced Sucrose Using High Pressure Homogenization}

Initially, sucrose and fructose crystals were carefully ground into a fine powder using a mortar and pestle, followed by milling at a rate of $3700 \mathrm{rpm}$ and a radius of $4 \mathrm{~cm}\left(3383 \mathrm{~L}\right.$, Thomas Wiley ${ }^{\circledR}$ Mini-Mill, Thomas Scientific, Swedesboro, NJ, USA). The suspension of sucrose crystals in solvent-free media was formed by mixing $20.0 \mathrm{~g}$ sucrose or fructose fine powder and $100 \mathrm{~g}$ of a crude-grade sugar ester, serving as the initial reaction medium, and placed on the magnetic stirrer plate, operated at $400 \mathrm{rpm}$ in a beaker of $100 \mathrm{~mL}$ and room temperature $\left(23.5 \pm 1.2^{\circ} \mathrm{C}\right)$ for $5 \mathrm{~min}$. Afterwards, the 
mixture was processed by a high speed homogenizer (VWR PowerMax AHS from Henry Troemner, Thorofare, NJ, USA) for $1 \mathrm{~min}$ at 12,000 rpm ( $805 \mathrm{~g})$. Then, the homogenized slurry was centrifuged at $800 \mathrm{rpm}(71 \mathrm{~g})$ for $0.5 \mathrm{~min}$, to remove larger particles via sedimentation. The supernatant was collected. The temperature of the resultant suspension after removal from the centrifuge was $24^{\circ} \mathrm{C}$. The samples were then treated by high pressure homogenation according to previously published procedures [22]. In brief, the sample was subjected to $\mathrm{HPH}$ at $300 \mathrm{MPa}$ using a high pressure valve homogenizer (Model FPG 12500, Stansted Fluid Power, Essex, UK). The homogenization chamber was cooled to $1{ }^{\circ} \mathrm{C}$ using a controlled temperature water bath (Isotemp 3016D, Fisher). In addition, a tubular heat exchanger was applied immediately after homogenization for maintaining the temperature of the samples at $24{ }^{\circ} \mathrm{C}$.

\subsection{Lipase-Catalyzed Sugar Oleate Synthesis Using Solvent-Free Suspensions}

The reactions were carried out according to the previous method developed by our group [23]. In brief, a $100 \mathrm{~mL}$ of stirred tank bioreactor (STBR) containing the reaction mixture in the absence of CALB was placed in a sealed desiccator that contained $\mathrm{CaSO}_{4}$ for 3 days at $350 \mathrm{rpm}$ and $65^{\circ} \mathrm{C}$. Reactions were conducted in a $100 \mathrm{~mL}$ beaker on a $20 \mathrm{~g}$ scale in a sealed desiccator operated on a hot plate/stirrer at $350 \mathrm{rpm}$ and $65^{\circ} \mathrm{C}$ for 4 days. All reactions were performed in duplicate, with data reported in the figures representing average values \pm standard deviation.

\subsection{Composition of Reaction Medium}

The water concentration for the reaction mixture was determined using a coulometric Karl-Fischer titrator (Denver Instrument Company, Aurora, CO, USA) in the presence of methanol, according to our previous paper [24]. The concentrations of oleic acid and sugar esters were measured by a HPLC system consisting of a dual-pump system from Agilent (Walnut Grove, CA, USA) and a model Mark III evaporative light scattering detector from WR Grace (Deerfield, IL, USA) with a reversed phase $\mathrm{C} 18$ column $(4.6 \mathrm{~mm} \times 250 \mathrm{~mm}$, pore diameter $5 \mu \mathrm{m})$ from Grace at $25^{\circ} \mathrm{C}$. An isocratic solvent system comprising of acetone/acetonitrile/acetic acid $(45 / 45 / 10 v / v / v)$ was delivered at flow rate of $1.0 \mathrm{~mL} \cdot \min ^{-1}[24]$.

Prior to measure the saccharide content using HPLC, $40 \mathrm{mg}$-sized aliquots of reaction mixture were mixed with n-hexane and water (500 $\mu \mathrm{L}$ of each), based on our pervious method [15] at $35^{\circ} \mathrm{C}$ for $2 \mathrm{~h}$ using a thermomixer (model 022670158, Eppendorf AG, Hamburg, Germany). An analytical Prevail Carbohydrate ES column $(4.6 \mathrm{~mm} \times 250 \mathrm{~mm}$, pore diameter $5 \mu \mathrm{m})$ from Grace was used to measure the saccharide content at $25^{\circ} \mathrm{C}$ with an isocratic solvent system containing acetonitrile/deionized water $(80 / 20 \mathrm{v} / \mathrm{v})$ at flow rate of $1 \mathrm{~mL} \cdot \mathrm{min}^{-1}$. Standard curves for saccharide concentration in a fatty acid/saccharide-fatty acid esters liquid phase versus peak area were obtained and it is independent of the reaction mixture's composition.

\subsection{Specific Gravity and Surface Tension}

The specific gravity of sugar esters at $22{ }^{\circ} \mathrm{C}$ was measured by using a calibrated metal pycnometer. The surface tension $(\gamma)$ of aqueous solutions of sucrose laurate, sucrose oleate and fructose oleate at several different concentrations $(C)$ and $22{ }^{\circ} \mathrm{C}$ was measured by a dynamic contact angle analyzer (model DCA 312 from Cahn, Newington, NH, USA). All measurements were repeated until the difference between two values was less than $0.2 \mathrm{mN} \cdot \mathrm{m}^{-1}$ at room temperature. Deionized water was used as a reference standard. Plot of $C$ (log scale) vs. $\gamma$ exhibit a linear decrease of $\gamma v s . \log C$ at low $C$, and a constant, minimal $\gamma$ at high $C$. The intersection of lines for the two regions was used to determine the critical micellar concentration (CMC). The slope of the low- $C$ region was used to calculate the surface excess $(\Gamma)$ according to Gibbs Equation [34]:

$$
\Gamma=-\frac{1}{R T} \frac{d \gamma}{d \ln C}
$$


where $R$ is the ideal gas law constant and $T$ is the temperature. The specific surface area $\left(A_{\mathrm{s}}\right)$ is inversely related to $\Gamma$ :

$$
A_{\mathrm{s}}=\left(\Gamma N_{\mathrm{A}}\right)^{-1}
$$

where $N_{\mathrm{A}}$ is Avogadro's number.

\subsection{Emulsification Capacity and Stability}

The emulsification capacity and stability were determined based on a previously published procedure with minor modifications [26]. Oil (hexadecane or dodecane, $1 \mathrm{~mL}$ ) was vigorously mixed with $4 \mathrm{~mL}$ of $2 \mathrm{~g} / \mathrm{L}$ aqueous surfactant solution (sucrose oleate, fructose oleate, sucrose laurate and Tween ${ }^{\circledR} 80$ ), then allowed to settle in the absence of stirring for $20 \mathrm{~min}$. The turbidity of the sample, reflecting the amount of oil emulsified, was measured as the absorbance at $600 \mathrm{~nm}$ versus time $(1.0 \mathrm{~cm}$ path length) using a model UV-1700 spectrophotometer from Shimadzu (Columbia, MD, USA).

\subsection{Antimicrobial Activity}

Antimicrobial activities of commercial and enzymatically synthesized sugar fatty acid esters against test microorganisms were estimated by a published method [27]. Four bacteria commonly causing foodborne illness were selected in this study. For Bacillus subtilis and Staphylococcus aureus, a broth containing meat extract $(1 \mathrm{~g} / \mathrm{L})$, yeast extract $(2 \mathrm{~g} / \mathrm{L})$, peptone $(5 \mathrm{~g} / \mathrm{L})$, and sodium chloride $(5 \mathrm{~g} / \mathrm{L})$ was used. For Lactobacillus plantarum and Pediococcus pentosaceus, a broth containing meat peptone $(15 \mathrm{~g} / \mathrm{L})$, sodium chloride $(1 \mathrm{~g} / \mathrm{L})$, glucose $(19 \mathrm{~g} / \mathrm{L})$, and glycerol $(5 \mathrm{~mL} / \mathrm{L})$ was employed. Liquid medium was inoculated with microorganism and incubated for $24 \mathrm{~h}$ at $30^{\circ} \mathrm{C}$ for B. subtilis and $37^{\circ} \mathrm{C}$ for L. plantarum, S. aureus and P. pentosaceus, based on different optimum growth temperatures of microorganisms. Stock solutions of sugar esters were diluted to the desired concentration in the liquid media. For better solubility and dispersion of sugar esters, $0.1 \%$ Tween ${ }^{\circledR} 80$ was added to the growth media. It was observed that the addition of $0.1 \%$ Tween ${ }^{\circledR} 80$ to cultures had no marked effect on cell growth when compared to controls (data not shown). The assays were prepared in test tubes for overnight culture microorganism suspension in the presence or absence of the sugar esters solutions.

Antimicrobial activity was accessed by measuring the turbidity suspension (optical density; $O D$ ) of microorganisms through UV-vis spectrophotometry at $600 \mathrm{~nm}$. A bacteria control without the addition of sugar ester was measured. An alcoholic control was prepared by addition of $1 \mathrm{~mL}$ of $96 \%$ ethanol instead of test sample solution and then inoculated with $1 \mathrm{~mL}$ bacterial suspension. The inhibition was calculated as the $O D$ of the sample containing microorganism and sugar fatty acid ester at the defined time of measurement $\left(O D_{\mathrm{x}}\right)$ compared to the $O D$ of the alcoholic control at defined time of measurement $\left(O D_{\mathrm{AC}}\right)$ :

$$
\text { Inhibition }(\%)=\left(\frac{O D_{\mathrm{AC}}-O D_{\mathrm{X}}}{O D_{\mathrm{AC}}}\right) \times 100
$$

\subsection{Antitumor Activity}

Ascitic tumor cells of Ehrlich carcinoma were cultured in Roswell Park Memorial Institute (RPMI, Buffalo, NY, US) 1640 supplemented with 4-(2-hydroxyethyl)-1-piperazineethanesulfonic acid (HEPES, $25 \mathrm{mM})$, L-glutamine $(2 \mathrm{mM})$, sodium bicarbonate $(25 \mathrm{mM}), 10 \%$ fetal bovine serum (FBS), 2-mercaptoethanol $(50 \mu \mathrm{m})$ and antibiotics (100 International Units (IU)/mL penicillin and $100 \mu \mathrm{g} / \mathrm{mL}$ streptomycin) at $37^{\circ} \mathrm{C}$ in a $5 \% \mathrm{CO}_{2}$ incubator. Viability and cell density were determined by the trypan blue dye exclusion test [28].

The 3-(4,5-dimethylthiazol-2-yl)-2,5-diphenyltetrazolium bromide (MTT) assay was conducted based on a well-established method in literature [29]. Cells were transferred to 96 well plates with a cell density of $\sim 2 \times 10^{5} \mathrm{~mL}^{-1}$ per well in the presence of $100 \mu \mathrm{L}$ of RPMI 1640 in a $\mathrm{CO}_{2}$ incubator for $24 \mathrm{~h}\left(37^{\circ} \mathrm{C}, 5 \% \mathrm{CO}_{2}\right)$. The medium was then removed and refilled with fresh medium including the different concentrations of sugar esters for $48 \mathrm{~h}$. The cells were incubated for $24-48 \mathrm{~h}$, followed 
by the addition of $20 \mu \mathrm{L}$ MTT, and stock solution ( $5 \mathrm{mg} / \mathrm{mL}$ in phosphate-buffered saline) to each well and incubation for $5 \mathrm{~h}$. After the medium was removed, $200 \mu \mathrm{L}$ of dimethyl sulfoxide was introduced into each well to dissolve the MTT metabolic product and the plate was shaken at $150 \mathrm{rpm}$ for $5 \mathrm{~min}$. The $O D$ of the sample was measured at $600 \mathrm{~nm}$. Untreated cells (basal) were used as a control (viability $=100 \%$ ). Results are expressed as $\%$ viability related to the control:

$$
\text { Cell viability }(\%)=(\text { A treated } / A \text { untreated }) \times 100
$$

where $A$ treated and $A$ untreated are the $O D$ of the treated and untreated cells, respectively.

\section{Conclusions}

In this study, the ester content achieved previously for solvent-free immobilized Rhizomucor miehei lipase-catalyzed synthesis of sucrose oleate and fructose oleate ( $81 \%-83 \%)$ was increased to $90.0 \%$ and $96.6 \%$ ester in four days at $65{ }^{\circ} \mathrm{C}$, respectively, by applying several innovative approaches. First, $\mathrm{HPH}$ was used to decrease the particle size of polysaccharides in the reaction medium to values $<4 \mu \mathrm{m}$, leading to higher concentrations of suspended saccharide. Second, the water activity of the lipases' microenvironment was lowered by employing $\mathrm{CaSO}_{4}$ to control the bioreactor's air headspace and using an immobilized lipase (from Candida antarctica B) possessing a hydrophobic matrix. The latter lipase altered the ester distribution in favor of diesters rather than monoesters, due to its regioselectivity. The resultant sugar esters lowered the surface tension to $<30 \mathrm{mN} / \mathrm{m}$, produced stable oil-in-water emulsions, and inhibited gram-positive foodborne pathogens and tumor cell growth to a similar extent as a commercially available sucrose ester. In conclusion, it was demonstrated that lipases can produce technical-grade biobased surfactants with utility in foods, cosmetics, personal care products, and pharmaceuticals under solvent-free conditions and in the absence of downstream purification.

Acknowledgments: Financial support was kindly supplied by the US Department of Agriculture (USA), Small Business Innovation Research (SBIR) Grant (2012-33610-19502). Authors also would like to thank Orlando J. Rojas, at Departments of Forest Biomaterials and Chemical \& Biomolecular Engineering, North Carolina State University, Raleigh, USA for allowing us to use the surface tensiometry equipment in his group.

Author Contributions: Ran Ye and Douglas G. Hayes conceived and designed the experiments; Ran Ye and Yuemeng Wang performed the experiments; Ran Ye analyzed the data; Federico M. Harte, Rachel Burton, and Anjun Liu contributed reagents, materials and analysis tools; Ran Ye wrote the paper. All authors have approved for the final version of the manuscript.

Conflicts of Interest: The authors declare no conflict of interest.

\section{Abbreviations}

The following abbreviations are used in this manuscript:

$\begin{array}{ll}\text { HIV } & \text { Anti-human immunodeficiency virus } \\ \text { FAO } & \text { Food and Agriculture Organization } \\ \text { HPH } & \text { High pressure homogenization } \\ \text { RML } & \text { Rhizomucor miehei lipase } \\ \text { CALB } & \text { Candida antarctica lipase B } \\ \text { PBBR } & \text { A packed-bed bioreactor } \\ \text { STBR } & \text { A stirred tank bioreactor } \\ \text { HLB } & \text { Hydrophilic-lipophilic balance } \\ \text { CMC } & \text { Critical micellar concentration } \\ \text { OD } & \text { Optical density } \\ \text { MTT } & \text { 3-(4,5-dimethylthiazol-2-yl)-2,5-diphenyltetrazolium bromide }\end{array}$

\section{References}

1. Pyo, S.; Hayes, D. Synthesis of saccharide-fatty acid ester biosurfactants catalyzed by lipase. In Biobased Surfactants and Detergents: Synthesis, Properties, and Applications; Hayes, D., Kitamoto, D., Solaiman, D., Ashby, D., Eds.; AOCS Press: Champaign, IL, USA, 2009; pp. 323-350. 
2. Gumel, A.M.; Annuar, M.S.M.; Heidelberg, T.; Chisti, Y. Lipase mediated synthesis of sugar fatty acid esters. Proc. Biochem. 2011, 46, 2079-2090. [CrossRef]

3. Foley, P.; Beach, E.S.; Zimmerman, J.B. Derivation and synthesis of renewable surfactants. Chem. Soc. Rev. 2012, 41, 1499-1518. [CrossRef] [PubMed]

4. Sanchez, S.A.; Gratton, E.; Zanocco, A.L.; Lemp, E.; Gunther, G. Sucrose monoester micelles size determined by fluorescence correlation spectroscopy (FCS). PLoS ONE 2011, 6, e29278. [CrossRef] [PubMed]

5. Kitaoka, M.; Imamura, K.; Hirakawa, Y.; Tahara, Y.; Kamiya, N.; Goto, M. Sucrose laurate-enhanced transcutaneous immunization with a solid-in-oil nanodispersion. MedChem Comm 2014, 5, 20-24. [CrossRef]

6. Shen, Y.; Sun, Y.; Sang, Z.; Sun, C.; Dai, Y.; Deng, Y. Synthesis, characterization, antibacterial and antifungal evaluation of novel monosaccharide esters. Molecules 2012, 17, 8661-8673. [CrossRef] [PubMed]

7. Xiao, D.; Ye, R.; Davidson, P.M.; Hayes, D.G.; Golden, D.A.; Zhong, Q. Sucrose monolaurate improves the efficacy of sodium hypochlorite against Escherichia coli O157:H7 on spinach. Int. J. Food Microbiol. 2011, 145, 64-68. [CrossRef] [PubMed]

8. Hoydonckx, H.E.; de Vos, D.E.; Chavan, S.A.; Jacobs, P.A. Esterification and transesterification of renewable chemicals. Top. Catal. 2004, 27, 83-96. [CrossRef]

9. Miao, S.; Callow, N.; Dashtbozorg, S.S.; Salager, J.-L.; Ju, L.-K. Ethylation of di-rhamnolipids: A green route to produce novel sugar fatty acid nonionic surfactants. J. Surf. Deterg. 2014, 17, 1069-1080. [CrossRef]

10. Gan, C.; Wang, H.; Zhao, Z.; Yin, B. Sugar-based ester quaternary ammonium compounds and their surfactant properties. J. Surf. Deterg. 2014, 17, 465-470. [CrossRef]

11. Zhao, H.; Liu, J.; Lv, F.; Ye, R.; Bie, X.; Zhang, C.; Lu, Z. Enzymatic synthesis of lard-based ascorbyl esters in a packed-bed reactor: Optimization by response surface methodology and evaluation of antioxidant properties. LWT Food Sci. Technol. 2014, 57, 393-399. [CrossRef]

12. Pyo, S.-H.; Hayes, D.G. Designs of bioreactor systems for solvent-free lipase-catalyzed synthesis of fructose-oleic acid esters. J. Am. Oil Chem. Soc. 2009, 86, 521-529. [CrossRef]

13. Ganske, F.; Bornscheuer, U.T. Lipase-catalyzed glucose fatty acid ester synthesis in ionic liquids. Org. Lett. 2005, 7, 3097-3098. [CrossRef] [PubMed]

14. Lu, Y.; Yan, R.; Ma, X.; Wang, Y. Synthesis and characterization of raffinose fatty acid monoesters under ultrasonic irradiation. Eur. Food Res. Technol. 2013, 237, 237-244. [CrossRef]

15. Ye, R.; Pyo, S.-H.; Hayes, D.G. Lipase-catalyzed synthesis of saccharide-fatty acid esters using suspensions of saccharide crystals in solvent-free media. J. Am. Oil Chem. Soc. 2010, 87, 281-293. [CrossRef]

16. Ye, R.; Hayes, D.G. Optimization of the solvent-free lipase-catalyzed synthesis of fructose-oleic acid ester through programming of water removal. J. Am. Oil Chem. Soc. 2011, 88, 1351-1359. [CrossRef]

17. Ye, R.; Hayes, D.G. Lipase-catalyzed synthesis of saccharide-fatty acid esters utilizing solvent-free suspensions: Effect of acyl donors and acceptors, and enzyme activity retention. J. Am. Oil Chem. Soc. 2012, 89, 455-463. [CrossRef]

18. Ye, R.; Hayes, D.G. Solvent-free lipase-catalysed synthesis of saccharide-fatty acid esters: Closed-loop bioreactor system with in situ formation of metastable suspensions. Biocatal. Biotransform. 2012, 30, $209-216$. [CrossRef]

19. Ye, R.; Hayes, D.G. Recent progress for lipase-catalyzed synthesis of sugar fatty acid esters. J. Oil Plam Res. 2014, 26, 355-365.

20. Ye, R.; Hayes, D.G.; Burton, R. Effects of particle size of sucrose suspensions and pre-incubation of enzymes on lipase-catalyzed synthesis of sucrose oleic acid esters. J. Am. Oil Chem. Soc. 2014, 91, 1891-1901. [CrossRef]

21. Food and Agricultural Organization of the United Nations (FAO); World Health Organization (WHO). Evaluation of Certain Food Additives and Contaminants: Seventy-Third [73rd] Report of the Joint FAO/WHO Expert Committee on Food Additives; WHO Technical Report Series 960; WHO: Geneva, Switzerland, 2011.

22. Zhao, H.; Song, Z. Migration of reactive trace compounds from Novozym ${ }^{\circledR} 435$ into organic solvents and ionic liquids. Biochem. Eng. J. 2010, 49, 113-118. [CrossRef]

23. Reyes-Duarte, D.; Lopez-Cortes, N.; Ferrer, M.; Plou, F.J.; Ballesteros, A. Parameters affecting productivity in the lipase-catalysed synthesis of sucrose palmitate. Biocatal. Biotransform. 2005, 23, 19-27. [CrossRef]

24. Branco, R.J.; Graber, M.; Denis, V.; Pleiss, J. Molecular mechanism of the hydration of Candida antarctica lipase B in the gas phase: Water adsorption isotherms and molecular dynamics simulations. ChemBioChem 2009, 10, 2913-2919. [CrossRef] [PubMed] 
25. Uppenberg, J.; Hansen, M.T.; Patkar, S.; Jones, T.A. The sequence, crystal structure determination and refinement of two crystal forms of lipase B from Candida antarctica. Structure 1994, 2, 293-308. [CrossRef]

26. Rodrigues, R.C.; Fernandez-Lafuente, R. Lipase from Rhizomucor miehei as a biocatalyst in fats and oils modification. J. Mol. Catal. B Enzym. 2010, 66, 15-32. [CrossRef]

27. Janssen, A.E.; Sjursnes, B.J.; Vakurov, A.V.; Halling, P.J. Kinetics of lipase-catalyzed esterification in organic media: Correct model and solvent effects on parameters. Enzym. Microb. Technol. 1999, 24, 463-470. [CrossRef]

28. Pogorzelski, S.; Watrobska-Swietlikowska, D.; Sznitowska, M. Surface tensometry studies on formulations of surfactants with preservatives as a tool for antimicrobial drug protection characterization. J. Biophys. Chem. 2012, 3, 324-333. [CrossRef]

29. Dawson, R.M.C.; Elliott, D.C.; Elliott, W.H.; Jones, K.M.U. Data for Biochemical Research; Oxford University Press: Oxford, UK, 1986; p. 580.

30. Soultani, S.; Ognier, S.; Engasser, J.-M.; Ghoul, M. Comparative study of some surface active properties of fructose esters and commercial sucrose esters. Coll. Surf. A Physicochem. Eng. Asp. 2003, 227, 35-44. [CrossRef]

31. Garofalakis, G.; Murray, B.S.; Sarney, D.B. Surface activity and critical aggregation concentration of pure sugar esters with different sugar headgroups. J. Coll. Int. Sci. 2000, 229, 391-398. [CrossRef] [PubMed]

32. Scheckermann, C.; Schlotterbeck, A.; Schmidt, M.; Wray, V.; Lang, S. Enzymatic monoacylation of fructose by two procedures. Enzym. Microb. Technol. 1995, 17, 157-162. [CrossRef]

33. Husband, F.; Sarney, D.; Barnard, M.; Wilde, P. Comparison of foaming and interfacial properties of pure sucrose monolaurates, dilaurate and commercial preparations. Food Hydrocoll. 1998, 12, 237-244. [CrossRef]

34. Adams, A.; Gast, A. Physical Chemistry of Surfaces; John Wiley and Sons: New York, NY, USA, 1997.

35. Neta, N.A.S.; dos Santos, J.C.S.; de Oliveira Sancho, S.; Rodrigues, S.; Gonçalves, L.R.B.; Rodrigues, L.R.; Teixeira, J.A. Enzymatic synthesis of sugar esters and their potential as surface-active stabilizers of coconut milk emulsions. Food Hydrocoll. 2012, 27, 324-331. [CrossRef]

36. Habulin, M.; Šabeder, S.; Knez, Ž. Enzymatic synthesis of sugar fatty acid esters in organic solvent and in supercritical carbon dioxide and their antimicrobial activity. J. Supercrit. Fluids 2008, 45, 338-345. [CrossRef]

37. Wagh, A.; Shen, S.; Shen, F.A.; Miller, C.D.; Walsh, M.K. Effect of lactose monolaurate on pathogenic and nonpathogenic bacteria. Appl. Environ. Microbiol. 2012, 78, 3465-3468. [CrossRef] [PubMed]

38. Zhang, X.; Song, F.; Taxipalati, M.; Wei, W.; Feng, F. Comparative study of surface-active properties and antimicrobial activities of disaccharide monoesters. PLoS ONE 2014, 9, e114845. [CrossRef] [PubMed]

39. Ferrer, M.; Soliveri, J.; Plou, F.J.; López-Cortés, N.; Reyes-Duarte, D.; Christensen, M.; Copa-Patiño, J.L.; Ballesteros, A. Synthesis of sugar esters in solvent mixtures by lipases from Thermomyces lanuginosus and Candida antarctica B, and their antimicrobial properties. Enzym. Microb. Technol. 2005, 36, 391-398. [CrossRef]

40. Iwami, Y.; Schachtele, C.; Yamada, T. Effect of sucrose monolaurate on acid production, levels of glycolytic intermediates, and enzyme activities of Streptococcus mutans NTCT 10449. J. Dental Res. 1995, 74, 1613-1617. [CrossRef]

41. Cho, H.-Y.; Tsuchido, T.; Ono, H.; Takano, M. Cell death of Bacillus subtilis caused by surfactants at low concentrations results from induced cell autolysis. J. Ferment. Bioeng. 1990, 70, 11-14. [CrossRef]

42. Kato, A.; Ando, K.; Tamura, G.; Arima, K. Effects of some fatty acid esters on the viability and transplantability of Ehrlich ascites tumor cells. Cancer Res. 1971, 31, 501-504. [PubMed]

43. Ferrer, M.; Perez, G.; Plou, F.J.; Castell, J.V.; Ballesteros, A. Antitumour activity of fatty acid maltotriose esters obtained by enzymatic synthesis. Biotechnol. Appl. Biochem. 2005, 42, 35-39. [PubMed]

44. Nishikawa, Y.; Yoshimoto, K.; Okabe, M.; Fukuoka, F. Chemical and biochemical studies on carbohydrate esters. III. Antitumor activity of unsaturated fatty acids and their ester derivatives against Ehrlich ascites carcinoma. Chem. Pharm. Bull. 1976, 24, 756-762. [CrossRef] [PubMed]

(C) 2016 by the authors; licensee MDPI, Basel, Switzerland. This article is an open access article distributed under the terms and conditions of the Creative Commons Attribution (CC-BY) license (http:/ / creativecommons.org/licenses/by/4.0/). 